\title{
BIBECHANA
}

A Multidisciplinary Journal of Science, Technology and Mathematics ISSN 2091-0762 (Print), 2382-5340 (Online)

Journal homepage: http://nepjol.info/index.php/BIBECHANA

Publisher: Research Council of Science and Technology, Biratnagar, Nepal

\section{Structural and thermal characterization of different types of cellulosic fibers}

\author{
Jyoti Giri 1,2,3, Ralf Lach ${ }^{4}$, Janak Sapkota ${ }^{5}$, Md. Abu Bin Hasan Susan 6 , Jean-Marc Saiter ${ }^{7}$, \\ Sven Henning ${ }^{8}$, Vimal Katiyar ${ }^{9}$, Rameshwar Adhikari ${ }^{1,3,10}$ \\ ${ }^{1}$ Central Department of Chemistry, Tribhuvan University, Kathmandu, Nepal \\ ${ }^{2}$ Department of Chemistry, Tri-Chandra Campus, Tribhuvan University, Kathmandu, Nepal \\ ${ }^{3}$ Nepal Polymer Institute (NPI),P. O. Box 24411, Kathmandu, Nepal \\ ${ }^{4}$ Polymer Service GmbH Merseburg (PSM), Merseburg, Germany \\ ${ }^{5}$ Institute of Polymer Processing, Department of Polymer Engineering and Science, \\ Montanuniversitaet Leoben, Otto-Glockel-Strasse 2, 800 Leoben, Austria \\ ${ }^{6}$ Department of Chemistry, Dhaka University, Dhaka, Bangladesh \\ ${ }^{7}$ Université de Normandie Rouen Laboratoire SMS Faculté des Sciences and Onyx Developpment, \\ Groupe-Nutriset, Rouen, France \\ ${ }^{8}$ Fraunhofer Institute for Microstructure of Materials and Systems (IMWS), Halle/S, Germany \\ ${ }^{9}$ Department of Chemical Engineering, Indian Institute of Technology (IIT), Guwahati, India \\ ${ }^{10}$ Research Centre of Applied Science and Technology (RECAST), Tribhuvan University,Kathmandu, Nepal \\ *Email: nepalpolymer@yahoo.com
}

Article history: Accepted 14 November, 2018

DOI: http://dx.doi.org/10.3126/bibechana.v16i0.21650

This work is licensed under the Creative Commons CC BY-NC License.

https://creativecommons.org/licenses/by-nc/4.0/

Micro- and nanocrystalline cellulose were extracted from wheat stalk (WS) using different thermomechanical and chemical treatments and characterized by spectroscopic, microscopic and diffraction techniques. The virgin WS fibers were found to be structurally quite similar to the commercial microcrystalline cellulose (MCC). Similar to the commercial one, the MCC extracted from the WS possessed intense infrared (IR) peaks whereas those peaks became more broader in the nanocrystalline cellulose (NCC) of the same origin, which can be attributed to possible breakdown of inter- and intramolecular H-bonding due to strong acid treatment of the MCC. Microscopic results revealed characteristic textures of the MCC and the NCC, the MCC being irregular bundles of the primary crystals bound together with the amorphous phase. The latter was found to disintegrate upon acid hydrolysis giving rise to the rod-shaped nanocrystals having much larger surface area and thus possessing more intense hydrophilic character. The MCC was found to be more stable than the NCC which can be attributed to the presence of protective and binding coating provided by the amorphous cellulosic matter.

Keywords: Natural fibers, Morphology, Electron microscopy, FTIR spectroscopy, Cellulose. 


\section{Introduction}

Polymers and fibers from renewable resources as well as their combinations in different forms have become attractive alternatives to conventional plastics, blends and composites for different practical applications [1,2]. Cellulose is one of the most abundant renewable natural resources. With the advancement in nanotechnology, the interests of polymer scientists have been attracted by micro- and nanocellulose of microbial as well as plants origin [1,2]. Among the natural fibers, cellulosics of various types and dimensionalities have special position in technical applications such as biodegradable tissue scaffolds, drug delivery vehicles and implantable biomaterials, aerospace engineering, functional devices and electronics.

The applications of such materials include not only in paints, inks, cosmetics, and coatings but also in textiles, flexible electronics, packaging materials, and optical appliances [3-6]. Nanocellulose composites have high mechanical properties and are non-toxic in nature and hence can be used in wide application areas.

It has been recognized that the natural fibers are being progressively introduced in nanocomposite materials sectors as reinforcing agents for the fabrication of lightweight materials. These fibers not only enhance the mechanical and thermal properties but can also induce ease of degradation in the composites with other polymers [7-9]. Biodegradation can also be observed based on the water absorption capacity of the composites, which is one of the criteria required to be easily attacked by microbes $[8,9]$.

In view of the potential opportunities of developing nanocellulose based enterprises based on agricultural wastes, a review on the extraction of micro- and nanocellulose was published a few years ago [10]. The objective of this paper is to discuss the structural and thermal properties of the microand nanocellulose materials that can be used for the fabrication of the degradable composite materials targeted for packaging applications.

\section{Experimental}

\subsection{Chemicals and sample preparation}

Chemicals such as absolute alcohol, $\mathrm{NaOH}, \mathrm{NaOCl}, \mathrm{NaHSO}$, and conc. $\mathrm{H} 2 \mathrm{SO} 4$ used in this work were purchased from Qualigen Fisher Scientific, Mumbai, India and were used without further purification.

Dry straw of the wheat (Triticum aestivum) was collected from Kathmandu and chopped into about 1 $\mathrm{mm}$ long fragments and then powdered properly with the help of a laboratory grinder. The wheat stalk (WS) powder was turned into micro crystalline cellulose (MCC) and nanocrystalline cellulose (NCC) using the procedures explained elsewhere [10].

\subsection{Characterization methods}

Fourier Transform Infrared (FTIR) Spectroscopy was performed on Perkin Elmer FTIR2000) in attenuated total reflectance (ATR) mode within the wavenumber range of 4000 to $700 \mathrm{~cm}-1$ with resolution of $20 \mathrm{~cm}-1$ in the ATR mode.

Scanning Electron Microscope (SEM, JOEL 6300) and Field Emission Scanning Electron Microscope (FESEM; Zeiss Gemin FESEM) were used to visualize the morphology of the fibers. The specimen surface was coated with a thin film of gold for SEM investigations. Additionally, Transmission Electron Microscope (FETEM, JOEL, JEM-2100F) was used to study the crystalline structure of the 
fibers. The specimens were prepared by dropping dilute solution of NCC powder in deionized water onto carbon coated copper grid followed by oven drying at $40{ }^{\circ} \mathrm{C}$ for $24 \mathrm{~h}$.

Thermogravimetric Analysis (TGA) of the samples was carried out using Mettler-Toledo, TGA/SDTA 851 equipment, under the inert atmosphere of dry nitrogen from $30^{\circ} \mathrm{C}$ to $600{ }^{\circ} \mathrm{C}$ with the heating rate of $20^{\circ} \mathrm{C} / \mathrm{min}$.

X-Ray Diffraction (XRD) was performed on X-ray diffractometer (Rigaku, TTRAX III 18KW and Bruker, Germany) running on the $\mathrm{Cu}-\mathrm{K} \alpha$ radiation $(\lambda=1.5406 \AA)$ at a scan rate of $0.05^{\circ}$ per $0.5 \mathrm{~s}$ for $2 \Theta$ range $5-50^{\circ}$.

\section{Results and Discussion}

\subsection{Spectroscopic characterization}

Fig. 1(a) presents the FTIR spectra of commercial MCC (named as MCC-com, HM400X) and the wheat stalk powder. The FTIR spectra are similar; only a few peaks of the MCC are found to be sharper and distinct. Both the spectra have broad absorption bands between $3600 \mathrm{~cm}-1$ to $3000 \mathrm{~cm}-1$ representing the $\mathrm{O}-\mathrm{H}$ stretching vibration and the strong intra- and intermolecular hydrogen bonds present in cellulose [11-14]. The FTIR peak located at $1593 \mathrm{~cm}-1$ represents the small bending vibration of $\mathrm{OH}$ bond. The axial C-H stretching of cellulose can be seen at $2894 \mathrm{~cm}-1$ which is more intense and sharper in MCC-com than in the WS. The $\mathrm{C}-\mathrm{H}$ stretching and $\mathrm{CH} 2$ wagging vibrations of cellulose are signature by correlated by the peaks located at $1369 \mathrm{~cm}-1$ and $1315 \mathrm{~cm}-1$, respectively [11]. Likewise, the characteristic anti-symmetric bridge stretching of $\mathrm{C}-\mathrm{O}$ and $\mathrm{C}-\mathrm{O}-\mathrm{C}$ pyranose ring vibration of cellulose is represented by the peak located at $1157 \mathrm{~cm}-1$ [11]. Similar type of $\mathrm{C}-\mathrm{O}$ stretching and $\mathrm{C}-\mathrm{O}-\mathrm{C}$ glycosidic bond stretching are attested by strong band at $1023 \mathrm{~cm}-1[15,16]$.

The absorption peak at $890 \mathrm{~cm}-1$ represents the typical structure of cellulose showing $\mathrm{C}-\mathrm{O}-\mathrm{C}$ stretching vibration for $\beta, 1,4$-glycosidic linkages $[13,17]$. In WS fibers, a few peaks (such as around $1300 \mathrm{~cm}-1)$ are quite different than commercial MCC (MCC-com), such as phenolic $\mathrm{C}-\mathrm{O}$ stretching which the signatures of presence of lignin and similar natural polymers in the neat WS. WS fibers further bear quite sharp peak corresponding to aromatic rings centered at $1604 \mathrm{~cm}-1$ for lignin in comparison to MCC-com [18, 19].

Fig. 1(b) compares the FTIR spectra of MCC with that of NCC obtained from the WS fibers. The MCC and NCC both have almost identical FTIR spectra as also reported by Satyamurthy and Vigneshwaran in cotton fibers [20]. The FTIR peaks of the NCC are weaker and less intense than the MCC, due to the reduction in crystallinity value and breakdown of numerous and intra- and intermolecular H-bonding between in the former $[13,19]$. The prominent cellulose peaks appear more intense in the MCC as compared to the WS due to the exposure of the MCC crystallites resulting from the dissolution of lignin binder and hemicellulose during chemical treatments. Few more cellulosic peaks are observed, in the MCC and $\mathrm{NCC}$, such as at $1642 \mathrm{~cm}-1$ representing carbonyl $\mathrm{C}=\mathrm{O}$ stretching of a saturated hydrocarbon [21].

It can be summarized that similar to the commercial one, the MCC extracted from the WS possessed intense peaks centered at $3329 \mathrm{~cm}-1$, whereas these peaks became broad and diffuse in the NCC of the same origin, which can be attributed to possible breakdown of inter- and intramolecular $\mathrm{H}$ bonding due to strong acid treatment. 


\subsection{Morphological characterization}

The microscopic techniques provide direct evidence of morphological details of the materials at different length scales. The electron micrographs give fiber surface morphology, including their size and dimensionality as well as their overall surface texture.

The scanning electron micrograph of the MCC derived from the WS fiber is shown in Fig. 2 (a). The MCC fibers are semi-crystalline in nature with length of approximately $25 \mu \mathrm{m}$ and width of $5 \mu \mathrm{m}$. In nature, the MCC has amorphous cellulose residing in between the micro-crystallites to form a long cylindrical structure with aspect ratio of approximately 5:1. The higher magnification SEM image in Fig. 2 (b) shows that the MCC bundles are made up of fine nanofibrillar texture. The dissolution of amorphous region of the WS fibers by different chemicals such as $\mathrm{NaOH}, \mathrm{NaOCl}$ and $\mathrm{H} 2 \mathrm{SO} 4$ can be attributed to the development of this texture.

The results reported on commercial MCC in an earlier work were also quite similar with respect to fibrillation and surface texture evolution, as well as shape and size of the MCC crystals [22-27].
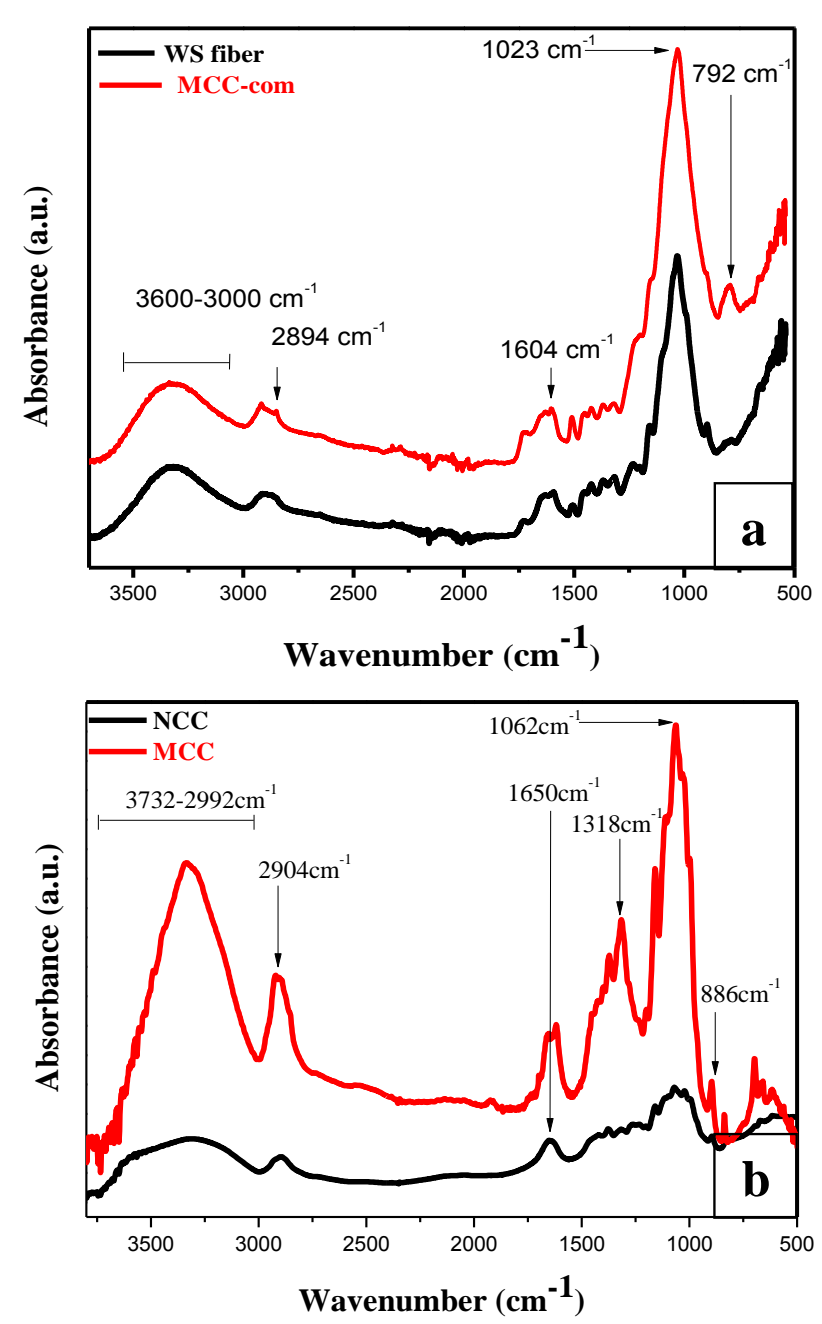

Fig. 1: FTIR spectra of different forms of natural fibers studied in this work: (a) pure wheat stalk (WS) powder compared to commercial MCC, and (b) the MCC and the NCC extracted from the WS powder.
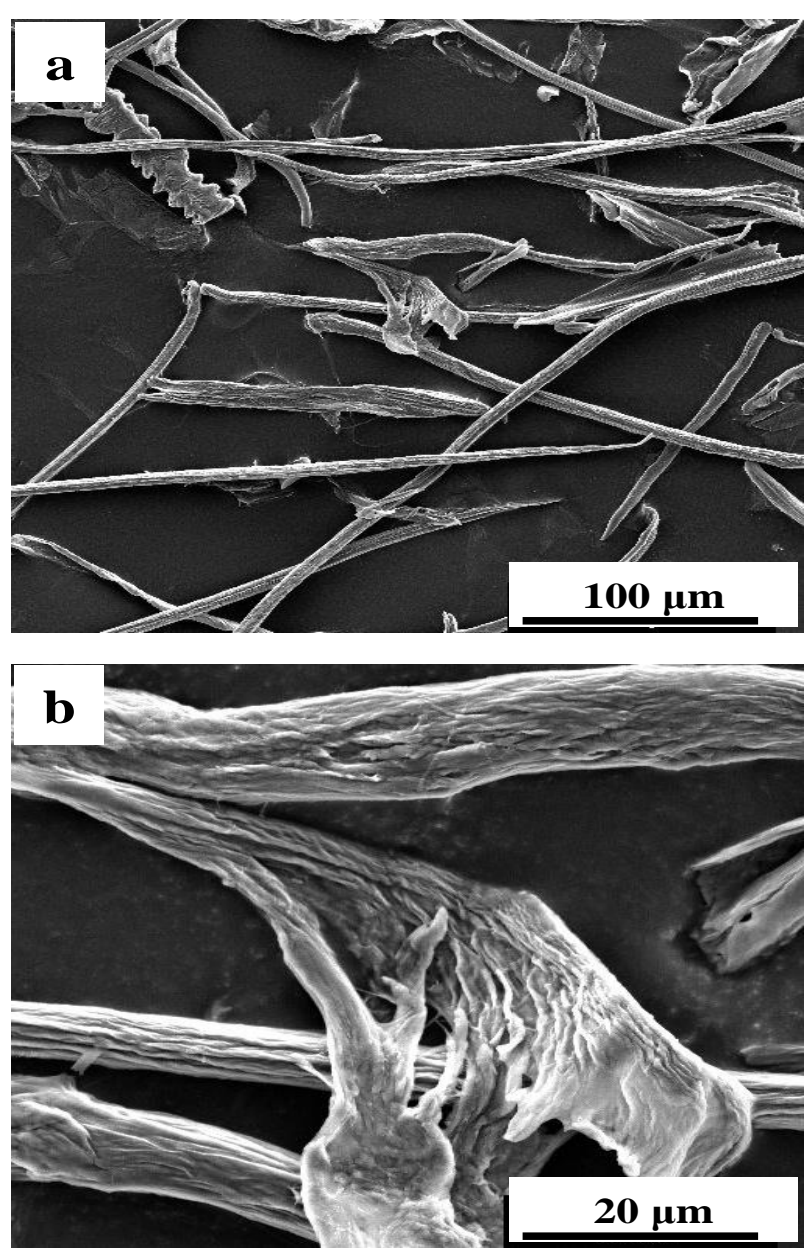

Fig. 2: Lower (top) and higher (bottom) magnifications of the SEM images of the MCC extracted from WS. 
FESEM technique is very useful for morphological studies of MCC and NCC under almost environmental condition. In this work, NCC powder was observed by FESEM, Fig. 3.

The synthesized bulk NCC powder in the dry form seems to have course, porous surface with large agglomeration. Only few NCC crystallites are projecting outside from the agglomerate, Fig. 3 (a). The shape of the NCC is more distinct in Fig. 3 (b), showing its rod shaped texture. The largest NCC aggregates observed has the dimension approximately $1 \mu \mathrm{m}$ long and $80 \mathrm{~nm}$ width, whereas the smallest one is about $200 \mathrm{~nm}$ long and $50 \mathrm{~nm}$ wide. These results are consistent with that reported in the literature [29-33].

The transmission electron micrographs presented in Fig. 4 (a) manifest that NCC fibers are in a bundle before nano-fibrillation out of the MCC, which are then exposed out on acid hydrolysis followed by the dissolution of amorphous region present between the nano-fibrils. These NCC get dispersed as rod-like crystals as shown in Fig. 4 (b). These crystals, being very hydrophilic in nature due to the presence of free-OH groups on their surfaces, can easily absorb water droplets or moisture, as demonstrated by cellular structures on the NCC crystals surfaces. The dimension of NCC from WS produced in this work is found to be approximately, $50 \mathrm{~nm}$ wide and $300 \mathrm{~nm}$ long. The results, in general, agree with the literature works [31-33].

From the microscopic results, it can be concluded that the MCC and NCC obtained from the WS fibers possess characteristic textures, the MCC being irregular bundles of the primary crystals bound together by the amorphous phase. The latter disintegrates upon acid hydrolysis giving rise to sharp rod-shaped nanocrystals which have much larger surface areas and thus possess strongly hydrophilic character.

The MCC and NCC fibers were studied also using XRD whereby the diffractograms were utilized to calculate the degree of crystallinity and d-spacing of the crystallites. In the first glance, the MCC spectrum shows a clear amorphous halo and a crystalline structure which the NCC spectrum has practically no amorphous halo showing the lack of amorphous phase. The NCC have quasi no amorphous halo showing the lack of amorphous phase.

The diffraction patterns of the MCC are shown in Fig. 5 (a). The XRD plot of the MCC shows two feeble $2 \Theta$ peaks in between $12-17^{\circ}$ as well as two sharp peaks at $20.04^{\circ}$ and $22.02^{\circ}$ which have been assigned to the cellulose I $[15,35-38]$. The high intensity of the peaks at $2 \Theta$ positions further indicates the highly crystalline nature of the cellulosic fibers.

The degree of crystallinity $(\chi c)$ values for the NCC (50\%) was found to be much higher than for the MCC (31\%) which has been attributed as the result of strong acid hydrolysis induced dissolution of the amorphous zone embedding the crystalline fibrils [39, 40].

\subsection{Thermal behavior}

The plot in Fig. 6 illustrates of thermogravimetric analysis of MCC and NCC. Both show two-step degradation. The MCC shows initial weight loss up to $7 \%$ at around $120{ }^{\circ} \mathrm{C}$ which corresponds to the removal of water and other volatile substances. The MCC itself starts to degrade at $225^{\circ} \mathrm{C}$, the major degradation occurs at Tmax of $373{ }^{\circ} \mathrm{C}$, which can be observed from the accompanying differential curve.

The complete thermal degradation occurred at around $400{ }^{\circ} \mathrm{C}$ with the char yield of $1.33 \%$ at $600{ }^{\circ} \mathrm{C}$ which is consistent with the values reported for the cellulosic materials of different origins [17]. The char yield limits the production of combustible gases and can even decrease the exothermic pyrolytic reaction inhibiting the thermal conductivity of the burning materials. 
Similarly, NCC also losses its weight by $10 \%$ due to removal of water and volatiles at around $120{ }^{\circ} \mathrm{C}$ while its degradation starts at $231{ }^{\circ} \mathrm{C}$ followed by the major degradation occurring at Tmax of 300 ${ }^{\circ} \mathrm{C}$. The complete degradation of the NCC occurs at $408{ }^{\circ} \mathrm{C}$ leaving the residual mass of $22.16 \%$ in the form of char after combustion at $600{ }^{\circ} \mathrm{C}$. Thus, on comparing thermal behavior, on can observe that the MCC is found to be more thermally stable than the NCC.
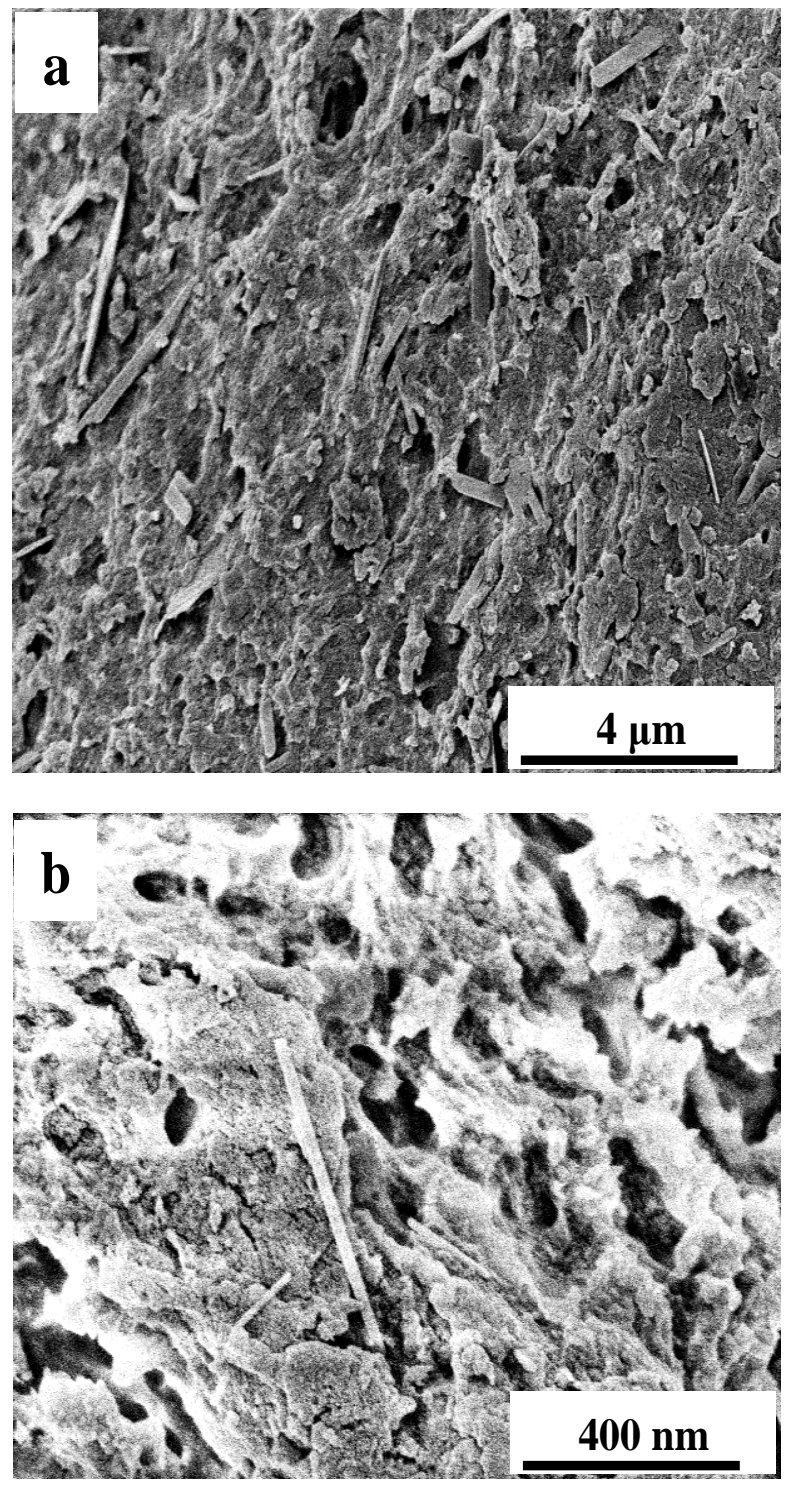

Fig. 3: Lower (a) and higher (b) magnifications of FESEM images showing nano-sized cellulose particles extracted from WS.
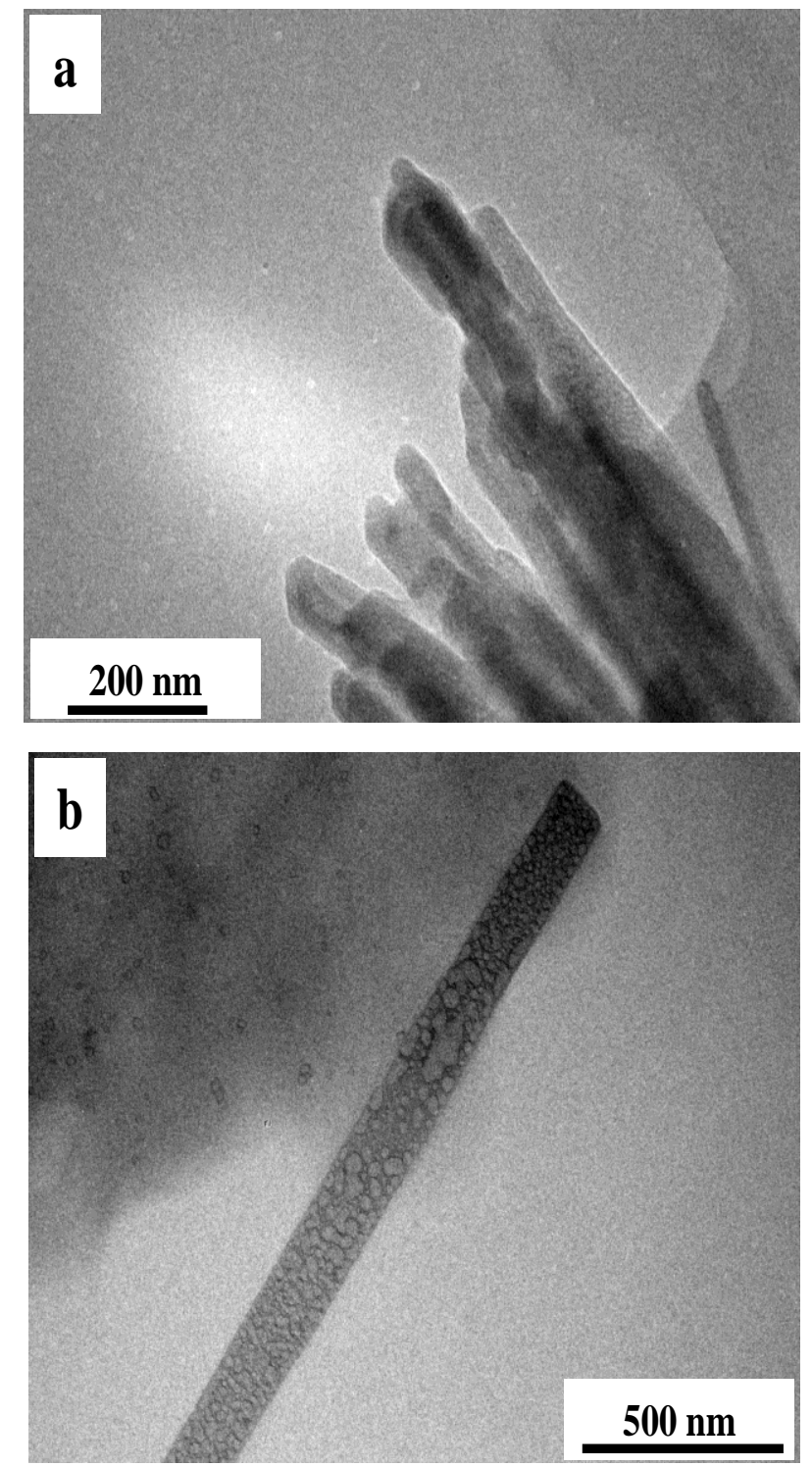

Fig. 4: TEM images of NCC extracted from MCC; (a) bundle showing NCC fibers in MCC, and (b) a single NCC crystallite dispersed from MCC. 

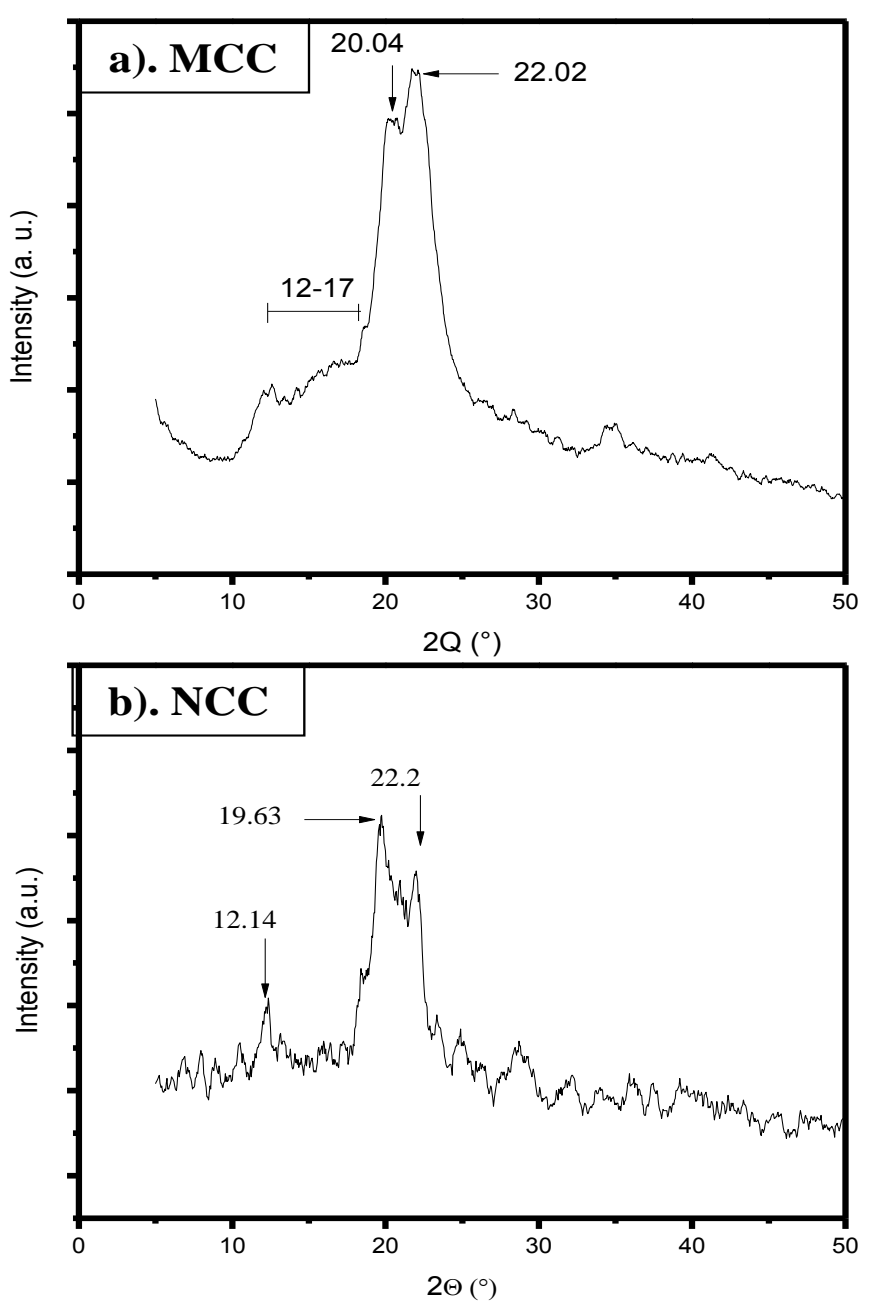

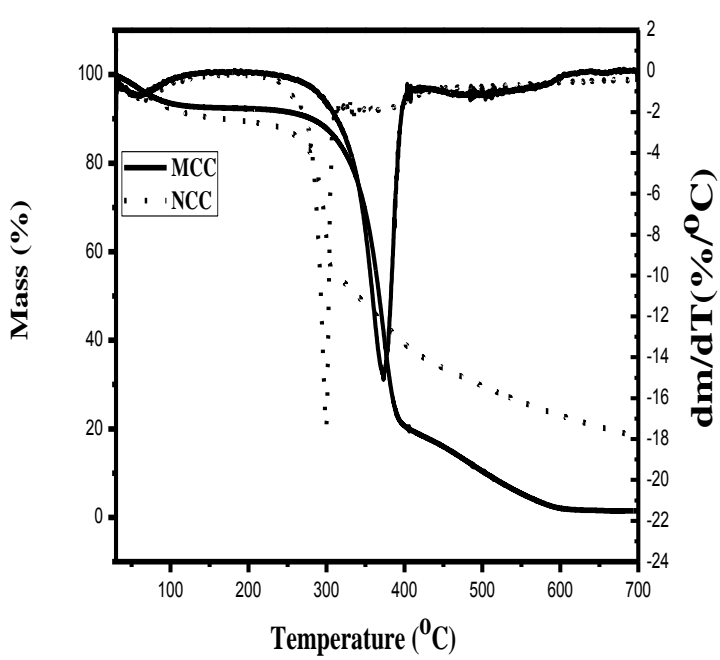

Fig. 6: TGA thermograms of MCC and NCC extracted from WS.

\section{Conclusions}

Micro- and nanocrystalline cellulose was extracted from wheat stalk using different thermomechanical and chemical treatments and characterized by spectroscopic, microscopic and diffraction techniques. The results presented in this paper can be concluded as follows:

Fig. 5: XRD patterns of MCC and NCC extracted from WS fibers.

(a) The spectroscopic analyses conclude that the virgin WS fibers are structurally quite similar to the commercial MCC. Similar to the commercial one, the MCC extracted from the WS possessed intense peaks centered at $3329 \mathrm{~cm}^{-1}$, whereas these peak became broad and diffuse in the NCC of the same origin, which can be attributed to possible breakdown of inter- and intramolecular $\mathrm{H}$ bonding due to strong acid treatment.

(b) From the microscopic evidences obtained from SEM and TEM, it is concluded that the MCC and NCC obtained from WS fibers are characterized by definite textures, the MCC being irregular bundles of the primary crystals bound together with the amorphous phase. The latter disintegrates upon acid hydrolysis to give rise to the rod-shaped sharp nanocrystals which have much larger surface area and thus intense hydrophilic character.

(c) The XRD results revealed that the natural fibers extracted from the WS predominantly contained Cellulose I form of the crystals whereby the nanofibrillation increased the degree of crystallinity by about two folds.

(d) The MCC and NCC thus prepared were found to be generally thermally stable while the NCC was found to be slightly less stable. The thermal stability of the MCC can be attributed to the security coating provided by the amorphous part of the cellulose which gets eliminated due to treatment with the strong acids. 


\section{Acknowledgements}

JG thanks Nepal Academy of Science and Technology (NAST) for providing $\mathrm{PhD}$ research Fellowship and further acknowledges the Indian National Science Academy (INSA) for providing the fellowship for a research stay at Indian Institute of Technology Guwahati (IITG), India.

\section{References}

[1] A. Dufresne, Nanocellulose: From Nature to High Performance Tailored Materials, Walter de Gruyter GmbH \& Co KG, Munich, Germany, 2017. ISBN 978-3-11-048041-2.

[2] S. Kalia, Lignocellulosic Composite Materials, Springer Series on Polymer and Composite Materials, Springer, Berlin, Germany, 2018. doi.org/10.1007/978-3-319-68696-7 5.

[3] T. T. Teeri, H. Brumer, G. Daniel, P. Gatenholm, Biomimetic engineering of cellulose-based materials. Trends. Biotech. 25 (2007) 299-306. doi.org/10.1016/j.tibtech.2007.05.002

[4] J. X. Sun, X. F. Sun, H. Zhao, R. C. Sun, Isolation and characterization of cellulose from sugarcane bagasse. Polym. Degrad. Stab. 84 (2004) 331-339. doi.org/10.1016/j.polymdegradstab.2004.02.008.

[5] D. Klemm, B. Philipp, T. Heinze, U. Heinze, W. Wagenknecht, Comprehensive Cellulose Chemistry, Functionalization of Cellulose, Volume II, WILEY-VCH Verlag, Weinheim, Germany, 1998. doi.org/10.1002/3527601937

[6] I. Siro, D. Plackett, Microfibrillated cellulose and new nanocomposite materials: a review, Cellulose. 17 (2010) 459-494. doi.org/10.1007/s10570-010-9405-y.

[7] A. Eldho, P. A. Elbi, B. Deepa, P. Jyotishkumar, L. A. Pothen, S. S. Narine, S. Thomas, X-ray diffraction and biodegradation analysis of green composites of natural rubber/nanocellulose, Polym. Degrad. Stab. 97 (2012) 2378-2387. doi.org/10.1016/j.polymdegradstab.2012.07.028.

[8] D. Bander, J. Sapkota, S. Josset, C. Weder, P. Tingaut, X. Gao, E. J. Foster, T. Zimmermann, Influence of mechanical treatments on the properties of cellulose nanofibers isolated from microcrystalline cellulose, React. Funct. Polym. 85 (2014) 134-141. doi.org/10.1016/j.reactfunctpolym.2014.09.009.

[9] N. L. Bhandari, W. Mormann, G.H. Michler, R. Adhikari, Functionalisation of bamboo and sisal fibres cellulose in ionic liquids, Mater. Res. Innovat. 17 (2013) 250-256. doi.org/10.1179/1433075X12Y.0000000068.

[10] J. Giri, R. Adhikari, A brief review on extraction of nanocellulose and its application, BIBECHANA 9 (2013) 81-87. doi.org/10.3126/bibechana.v9i0.7179.

[11] R. Gemci, Examining the effects of mercerization process applied under different conditions to imensional stability, Scientific Research and Essays 5 (2010) 560-571.

[12] N.A. Ibrahim, Effect of fiber treatment on the mechanical properties of kenaf fiber-ecoflex composites, J. Reinf. Plast. Comp. 29 (2010) 2192-2198. doi.org/10.1177/0731684409347592.

[13] P. Manimaran, P. Senthamaraikanna, M. R. Sanjay, M. K. Marichelvam, M. Jawaid, Study on characterization of Furcraea foetida new natural fiber as composite reinforcement for lightweight applications, Carbohydr. Polym. 181 (2018) 650-658. doi.org/10.1016/j.carbpol.2017.11.099.

[14] J.H. Pang, X. Liu, M. Wu, Y.Y. Wu, X.M. Zhang, R.C. Sun, Fabrication and characterization of regenerated cellulose films using different liquids, J. Spectr. (2014) Article ID 214057 (8 pages). doi.org/10.1155/2014/214057.

[15] M.B. Guerrero, L.A.P. Maqueda, R. Artiaga, P.E.S. Jiménez, J.P. Cosp, Structural and chemical characteristics of sisal fiber and its components: effect of washing and grinding, J. Nat. Fib. 14 (2016) 26-39. doi.org/10.1080/15440478.2015.1137529.

[16] M.E. Sakhawy, S. Kamel, A. Salama, H.A. S. Tohamy, Preparation and infrared study of cellulose based amphiphilic materials. Cellulose Chem. Technol. 52 (2018) 193-200.

[17] C.S. $\mathrm{Wu}$, Characterization of cellulose acetate-reinforced aliphatic- aromatic copolyester composites, Carbohydr. Polym. 87 (2012) 1249-1256. doi.org/10.1016/j.carbpol.2011.09.009. 
[18] J.G. Gwon, S.Y. Lee, G.H. Doh, J.H. Kim, Characterization of chemically modified wood fibers using FTIR spectroscopy for biocomposites, J. Appl. Polym. Sci. 116 (2010) 3212-3219. doi.org/10.1002/app.31746.

[19] M. Pan, X. Zhou, M. Chen, Cellulose nanowhiskers isolation and properties from acid hydrolysis combined with high pressure homogenization, BioResources. 8 (2013) 933-943.

[20] P. Satyamurthy, N. Vigneshwaran, A novel process for synthesis of spherical nanocellulose by controlled hydrolysis of microcrystalline cellulose using anaerobic microbial consortium, Enzyme Microb. Technol. 52 (2013) 20-25. doi.org/10.1016/j.enzmictec.2012.09.002

[21] N. A. Rosli, I. Ahmad, I. Abdullah, Isolation and characterization of cellulose nanocrystals from Agave angustifolia fibre, Bioresources 8 (2013) 1893-1908.

[22] D. M. Panaitescu, A. N. Frone, M. Ghiurea, C. I. Spataru, C. Radovici, M. D. Iorga, 'Properties of polymer composites with cellulose microfibrils', In: Brahim Attaf (Ed.), Advances in Composites Materials-Ecodesign and Analysis, Intechopen, Chapter 5, pp. 103-122, 2011. ISBN: 978-953-307-150-3.

[23] K.P. Rajan, N. R. Veena, Hanna J. Maria, R. Rajan, M. Skrifvars, K. Joseph, Extraction of bamboo microfibrils and development of biocomposites based on polyhydroxybutyrate and bamboo microfibrils, J. Compos. Mater. 45 (2010) 1325-1329. doi.org/10.1177/0021998310381543.

[24] R. Krishnaprasad, N. R. Veena, Hanna J. Maria, R. Rajan, M. Skrifvars, K. Joseph, Mechanical and thermal properties of bamboo microfibril reinforced polyhydroxybutyrate biocomposites, J. Polym. Env. 17 (2009) 109-114. doi.org/10.1007/s10924-009-0127-x.

[25] M. Das, D. Chakraborty, The effect of alkalization and fiber loading on the mechanical properties of bamboo fiber composites, part1:-polyester resin matrix. J. Appl. Polym. Sci. 112 (2009) 489-495. doi.org/10.1002/app.29342.

[26] E. M. Cadena Chamoro, J. M. Velez, J. F. Santa, V. Otalvaro G., Natural fibers from plantain pseudostem (Musa Paradisiaca) for use in fiber-reinforced composites, J. Nat. Fib. 14 (2017) 678-690. doi.org/10.1080/15440478.2016.1266295.

[27] D. L. Vinayak, V. Guna, D. Madhavi, M. Arpitha, N. Reddy, Ricins communis plant residues as a source for natural cellulose fiber potentially exploitable in polymer composites. Ind. Crops Prod. 100 (2017) 126-131. doi.org/10.1016/j.indcrop.2017.02.019.

[28] G. C. Carrasco, A. Miettinen, C. Hendriks, E. Gamstedt, M. Kataja, J. Cuppoletti, Structural characterization of Kraft pulp fibres and their nanofibrillated materials for biodegradable composite applications, in J. Cuppoletti (Ed.), 'Nanocomposites and Polymers with Analytical Methods', Chapter 10, pp. 243-260, Intechopen 2011. doi.org/10.5772/21580.

[29] W. Gauitua, A. Ballerini, J. Zhang, Polymer nanocomposites: synthetic and natural fillers a review. Maderas Clencia y Technologia 7 (2005) 159-178. doi.org/10.4067/S0718-221X2005000300002.

[30] F. Kramer, D. Klemm, D. Schumann, N. Heßler, F. Wesarg, W. Fried, D. Stadermann, Nanocellulose polymer composites as innovative pool for (bio)material development, Macromol. Symp. 244 (2006) 136-148. doi.org/10.1002/masy.200651213.

[31] D. Y. Liu, X. W. Yuan, D. Bhattacharyya, A. J. Easteal, Characterisation of solution cast cellulose nanofibre-reinforced poly(lactic acid), eXPRESS Polym. Lett. 4 (2010) 26-31. doi.org/10.3144/expresspolymlett.2010.5.

[32] M. J. Cho, B. D. Park, Tensile and properties of nanocellulose-reinforced poly(vinyl alcohol) nanocomposites, J. Ind. Eng. Chem. 17 (2011) 36-40. doi.org/10.1016/j.jiec.2010.10.006.

[33] S. Mueller, C. Weder, E. J. Foster, Isolation of cellulose nanocrystals from pseudostems of banana plants, RSC Adv. 4 (2014) 907-915. doi.org/10.1039/C3RA46390G.

[34] J. Li, X. Wei, Q. Wang, J. Chen, G. Chang, L. Kong, J. Su, Y. Liu. Homogeneous isolation of nanocellulose from sugarcane bagasse by high pressure homogenization, Carbohydr. Polym. 90 (2012) 1609-1613. doi.org/10.1016/j.carbpol.2012.07.038.

[35] A. Sonia, K.P. Dasan, Cellulose microfibers (CMF)/poly(ethylene-co-vinyl acetate) (EVA) composites for food packaging applications: A study based on barrier and biodegradable behavior, J. Food Eng. 118 (2013) 78-89. doi.org/10.1016/j.jfoodeng.2013.03.020. 
[36] E. D. M. Teixeira, A. C. Correa, A. Manzoli, F. D. L. Leite, C. R. D. Oliveira, L. H. C. Mattoso, Cellulose nanofibers from white and naturally colored cotton fibers, Cellulose. 17(2010) 595-606. doi.org/10.1007/s10570-010-9403-0

[37] M. Adsul, S. K. Soni, S. K. Bhargava, V. Bansal, Facile approach for the dispersion of regenerated cellulose in aqueous system in the form of nanoparticles, Biomacromolecules 13 (2012) 2890-2895. doi.org/10.1021/bm3009022.

[38] A. Mandal, D. Chakrabarty, Isolation of nanocellulose from waste sugarcane bagasse (SCB) and its characterization, Carbohydr. Polym. 86 (2011) 1291-1299. doi.org/10.1016/j.carbpol.2011.06.030.

[39] B. M. Cherian, A. L. Leao, S. Ferreira, D. Souza, S. Thomas, L. A. Pothan, M. Kottaisamy, Isolation of nanocellulose from pineapple leaf fibres by steam explosion, Carbohydr. Polym. 81 (2010) 720-725. doi.org/10.1016/j.carbpol.2010.03.046.

[40] D. Dai, M. Fan, Characteristic and performance of elementary hemp fibre, Mat. Sci. Appl. 1 (2010) 336342. doi.org/10.4236/msa.2010.16049. 